\title{
APRENDIZAGEM ATIVA A PARTIR DE COMPETIÇÕES: CONCURSO DE TALUDES
}

Fernando Antônio de Carvalho - fernando.carvalho@engenharia.ufjf.br

Universidade Federal de Juiz de Fora - Faculdade de Engenharia

Rua José Lourenço Kelmer, s/n-Campus Universitário, São Pedro

36036-900 - Juiz de Fora - Minas Gerais

Iasmin Ferreira Nery - iasmin.nery@engenharia.ufjf.br

Universidade Federal de Juiz de Fora - Faculdade de Engenharia

Rua José Lourenço Kelmer, s/n-Campus Universitário, São Pedro

36036-900 - Juiz de Fora - Minas Gerais

Luiz.Tadeu Dias Júnior - luiz.tadeu@engenharia.ufjf.br

Universidade Federal de Juiz de Fora - Faculdade de Engenharia

Rua José Lourenço Kelmer, s/n-Campus Universitário, São Pedro

36036-900 - Juiz de Fora - Minas Gerais

Renan de Carvalho Pinto - renan.carvalho@engenharia.ufjf.br

Universidade Federal de Juiz de Fora - Faculdade de Engenharia

Rua José Lourenço Kelmer, s/n-Campus Universitário, São Pedro 36036-900 - Juiz de Fora - Minas Gerais

Yuri Mariano Carvalho - yuri.mariano@engenharia.ufjf.br

Universidade Federal de Juiz de Fora - Faculdade de Engenharia

Rua José Lourenço Kelmer, s/n-Campus Universitário, São Pedro

36036-900 - Juiz de Fora - Minas Gerais

Júlia Righide Almeida-julia.righi@engenharia.ufjf.br

Universidade Federal de Juiz de Fora - Departamento de Transportes e Geotecnia

Rua José Lourenço Kelmer, s/n-Campus Universitário, São Pedro

36036-900 - Juiz de Fora - Minas Gerais

Resumo: A realização de competições para incentivar a aprendizagem ativa em cursos de Engenharia é algo comum nas instituições brasileiras, visto que promove ganhos tanto para organizadores quanto para competidores. O Concurso de Taludes, em especial, permite a aprendizagem e aplicação práticas de conceitos geotécnicos. Visto que edições anteriores da atividade em outras universidades apresentaram problemas relacionados à segurança dos participantes, o PET Engenharia Civil da UFJF elaborou versão própria da competição a fim de incentivar a realização do concurso. Este artigo sintetiza a organização e os resultados obtidos com o evento, que foi aclamado pelos discentes que participaram. Dessa forma, transformou-se um concurso quase extinto nas universidades brasileiras em um evento seguro e de fácil execução pelos participantes.

Palavras-chave: Programa de Educação Tutorial. Engenharia Geotécnica. Educação em Engenharia. Desafios. 


\section{INTRODUÇÃO}

As atuais Diretrizes Curriculares Nacionais (DCNs) do Curso de Graduação em Engenharia propõe um novo paradigma para a dinâmica de ensino-aprendizagem: desenvolver competências nos estudantes durante a graduação, e não apenas fornecer elementos para que eles as desenvolvam posteriormente (OLIVEIRA, 2019).

Pelo país, diversas universidades realizam concursos e desafios para incentivar a aprendizagem ativa de estudantes de Engenharia (COSTA et al., 2019; OLIVEIRA et al., 2017; ZORZAN et al., 2017). Realizar competições implica ganhos tanto para os estudantes que as organizam (CARVALHO et al., 2019) quanto para aqueles que participam da atividade (OLIVEIRA et al., 2017). Na Universidade Federal de Juiz de Fora (UFJF), o Programa de Educação Tutorial de Engenharia Civil (PET Engenharia Civil) realiza, desde 2008, competições estudantis voltadas à Engenharia Estrutural (concursos para montagem de pontes com madeira ou papel; e para a montagem de estruturas com o Mola Structural $\mathrm{Kit}^{\circledR}$ ). Em 2019, o grupo realizou a primeira edição de um desafio voltado à Geotecnia: o Concurso de Taludes.

Inspirados no trabalho do PET Engenharia Civil da Universidade Federal do Paraná (UFPR) (ZORZAN et al., 2017), pioneiros na realização da atividade, e nas discussões no VI Congresso Nacional dos Grupos PET de Engenharia Civil (VI CONPET Civil) quanto aos riscos associados à realização da competição (interrompida após sua segunda edição, em 2018), o PET Engenharia Civil da UFJF reestruturou o concurso para que fosse mais seguro para competidores e organizadores. Dessa forma, estimulou-se a participação e a aprendizagem lúdica também por estudantes dos períodos iniciais.

Portanto, objetiva-se com este trabalho ilustrar o processo de organização do concurso e a sua forma final, a fim de incentivar a reprodução por outras instituições de ensino.

\section{METODOLOGIA}

A Figura 1 esquematiza as principais etapas para a organização e execução do concurso.

Figura 1 - Planejamento do Concurso de Taludes.

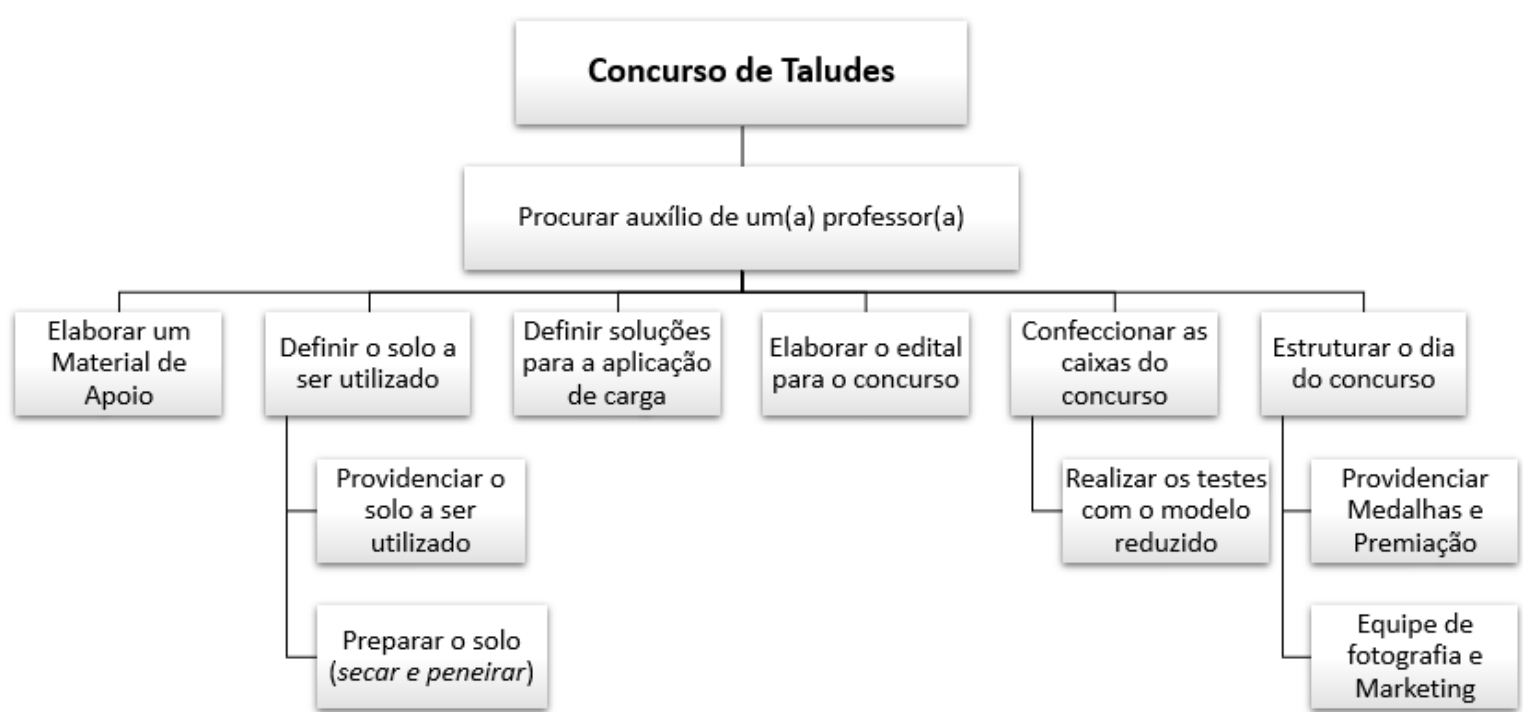

Fonte: Arquivo interno. 
A atividade foi realizada no dia 18 de setembro de 2019 (segundo semestre letivo do ano) na Faculdade de Engenharia, durante a XLII Semana da Engenharia + III Semana da Saúde Mental, organizada pelo Diretório Acadêmico Clorindo Burnier da Faculdade de Engenharia (DAEng).

Para planejar o concurso, contou-se, inicialmente, com o auxílio de professores do Departamento de Transportes e Geotecnia (que contribuíram para desenvolver um concurso seguro e atrativo aos estudantes de períodos iniciais por não demandar inúmeros conhecimentos técnicos) e de funcionários terceirizados da Instituição de Ensino Superior (que disponibilizaram seu tempo e sua mão de obra em atividades variadas).

O contato com os professores permitiu elaborar um Material de Apoio para os participantes do concurso, a fim de aumentar a adesão, visto que alguns alunos ainda não haviam cursado disciplinas específicas sobre taludes e estruturas de contenção, mas gostariam de participar dessa atividade. Além disso, definiu-se que o solo a ser utilizado no dia do concurso para criação do talude em escala reduzida seria areia média, ou seja, passante na peneira $\mathrm{n}^{\circ} 10(\varnothing 2,00 \mathrm{~mm})$ e retido na peneira $\mathrm{n}^{\circ} 30(\varnothing 0,59 \mathrm{~mm})$.

Para o trabalho com o solo, foram utilizados os seguintes laboratórios da Faculdade de Engenharia da UFJF:

- Laboratório de Mecânica dos Solos, utilizado para realizar ensaios para classificar o material, determinar seus índices de vazios máximo e mínimo (emáx e emin) e peneirá-lo para selecionar a faixa granulométrica do material. Também foram realizados ensaios com protótipos de taludes para verificar as cargas suportadas e o comportamento do modelo com as dimensões idênticas ao concurso. Modelou-se, também, um protótipo de talude com o software GeoSlope ${ }^{\circledR}$, programa de análise de estabilidade com o intuito de definir a faixa de inclinação e previsão das cargas máximas para ruptura;

- Laboratório de Materiais de Construção Civil, utilizado para secar e armazenar o solo utilizado no dia do concurso. A razão de se utilizar o solo seco será tratado posteriormente em outras seções; e

- Laboratório de Resistência dos Materiais, que disponibilizou anilhas de aço para testes de carga.

Para solucionar o método de aplicação de carga nos taludes e garantir o mínimo de uniformidade na distribuição dessas cargas ao longo da crista do talude, a organização elaborou uma estrutura de madeira, em formato cúbico, e a inseriu abaixo de uma placa de aço com peso de $5 \mathrm{~kg}$, considerado no total das cargas suportadas. Como as dimensões da placa de aço eram maiores que a menor dimensão da caixa, a chapa manteve as anilhas agrupadas sobre a caixa no momento da ruptura (Figura 2). Sendo assim, conseguiu-se realizar um mecanismo simples e seguro para o teste de cargas.

Quanto às caixas utilizadas na competição para construir os taludes, optou-se pelo modelo abaixo (Figura 3), feita em madeira de Pinus. 
Figura 2 - Aplicação da carga, à esquerda, e momento de ruptura, à direita.

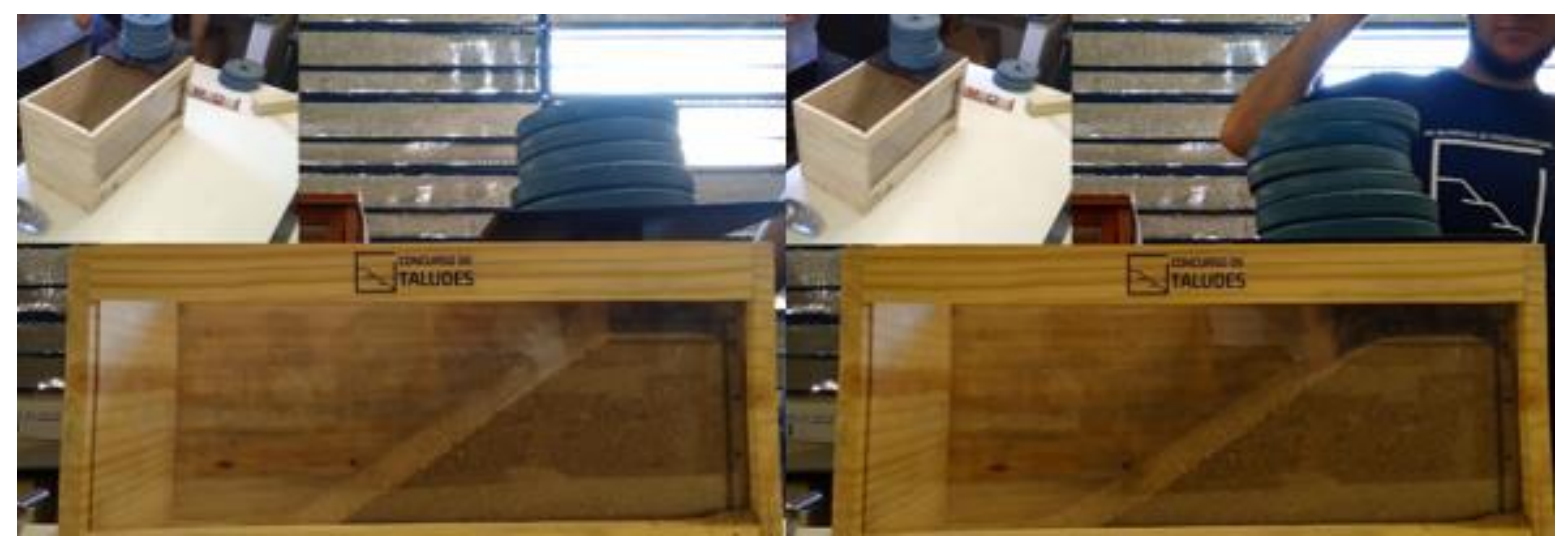

Fonte: Arquivo interno.

Figura 3 - Modelo da caixa de madeira utilizada no concurso.

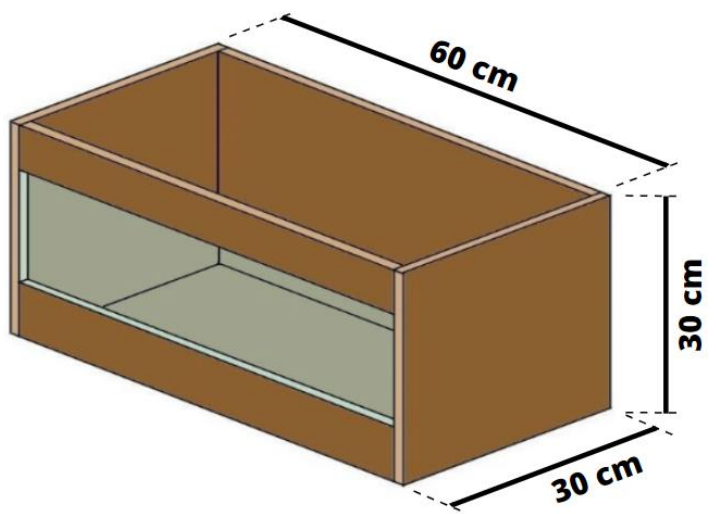

Fonte: Arquivo interno.

Essa definição trouxe consigo uma solução viável tanto economicamente quanto logisticamente, já que o custo aproximado de todas as caixas (8 no total) foi de $\mathrm{R} \$ 350,00$. A chapa de Poliestireno PS transparente (dimensões: $56 \mathrm{~cm}$ x $28 \mathrm{~cm}$ ) com 3 milímetros de espessura foi utilizada para possibilitar que as equipes participantes e a plateia do concurso acompanhassem a colocação do solo para conformação do talude e também o momento da ruptura com a aplicação das cargas. As caixas foram lixadas para conferir maior durabilidade às mesmas.

Por fim, os taludes foram modelados e testados em laboratório com o solo a ser utilizado no dia do evento.

O edital da competição foi elaborado estabelecendo um número máximo de 8 equipes compostas por 3 ou 4 participantes, que deveriam ser estudantes de Engenharia da UFJF, independentemente do semestre no qual estivessem matriculados. As equipes tiveram que seguir regras estabelecidas em edital para a validação do seu modelo e prosseguimento para o teste de carga. Dentre elas, pode-se citar:

4.2. Cada grupo poderá participar com apenas um talude feito com o material estipulado e fornecido pela comissão organizadora, a saber no momento da montagem. [...]

4.5. O talude deverá ser montado dentro da caixa de madeira disponibilizada pela organização. A face superior do talude deverá ter dimensões mínimas de $10 \mathrm{~cm}$ x $10 \mathrm{~cm}$, compatíveis com a chapa de metal utilizada para uniformização da aplicação da carga. 
4.6. Ao fim da montagem, a altura do talude deverá ser maior que $20 \mathrm{~cm}$ e menor que $22 \mathrm{~cm}$, delimitada pelas fitas colocadas na chapa de Poliestireno PS transparente. [...]

4.9. O tempo de execução será de, no máximo, 45 minutos. (PET ENGENHARIA CIVIL - UFJF, 2019).

A nota final de cada equipe considerou três fatores, quais sejam: a carga suportada pelo talude (peso 3,5), o tempo para execução do mesmo (peso 2,5), e a economia de material (peso 4.0). O critério associado à carga suportada pelo talude foi definido para avaliar a capacidade prática dos estudantes de aplicarem seus conhecimentos técnicos sobre geotecnia na construção da obra de terra. Os demais critérios (agilidade e economia na construção do talude) foram definidos para incentivar a produtividade e a economia de recursos naturais. As fórmulas para cada cálculo estão explicitadas em edital (PET ENGENHARIA CIVIL, 2019).

Além disso, a equipe deveria informar aos fiscais (membros do PET Engenharia Civil da UFJF), antes do início da montagem, o ângulo de inclinação desejado na montagem do modelo de talude, podendo ser penalizada por desviar do ângulo almejado.

Visto que o material seria revelado durante o concurso, a organização disponibilizou para estudo em local a parte quatro amostras com possíveis tipos de solo a serem empregados na competição.

No procedimento de ruptura, a primeira carga (placa de aço) era posicionada por um membro da comissão organizadora sobre o eixo vertical que passa pelo centro de gravidade (CG) do bloco de madeira alocado no topo da crista do talude. As demais cargas foram posicionadas por algum membro da equipe de forma a sempre manter, na medida do possível, a estabilidade do modelo geotécnico. Todos os participantes e espectadores da competição foram contemplados, antes do início das atividades, com uma breve explicação dada por uma professora especialista no tema acerca das melhores formas de construir um talude nos modelos que a competição exigia, facilitando assim a dinâmica das equipes.

Ao final do concurso foram solicitados feedbacks por meio de formulário eletrônico aos participantes, tanto daqueles que tiveram equipes inscritas quanto dos que apenas assistiram à competição. Para os alunos que participaram da montagem dos modelos geotécnicos foram direcionadas perguntas quanto ao modelo da competição (como edital, material de apoio, competição em si, entre outras questões). Para os outros participantes questionou-se sobre a organização do evento (tempo de competição, conhecimentos transmitidos e entusiasmo dos apresentadores).

\section{RESULTADOS E DISCUSSÃO}

O material inicialmente escolhido foi a areia natural simples. A heterogeneidade do material, no entanto, não fornecia ângulo de atrito preciso, pois a areia detinha formas e dimensões variadas (PINTO, 2002). Logo, optou-se por peneirar todo o material do concurso, a fim de homogeneizá-lo - cerca de $500 \mathrm{~kg}$.

Ao peneirar a areia, percebeu-se que cerca de $60 \%$ do material era de granulometria média. Mesmo que solos com areias mais finas rompam com cargas inferiores a solos com areias mais grossas (PINTO, 2002), optou-se por manter a areia média, evitando o desperdício de material. O peneiramento foi realizado manualmente, a fim de agilizar o processo (visto que haviam somente dois peneiradores automáticos nos laboratórios da Universidade). A grande quantidade de material secado em estufa e posteriormente peneirado gerou uma alta carga de trabalho, de cerca de $50 \mathrm{~h}$.

Os esforços investidos na organização da atividade implicaram em um concurso mais acessível a estudantes de todos os períodos da Engenharia - o que pode contribuir para 


\section{COBENCE de Educação em Engenharia 2020 da $A B E N G E$}

"Os desafios para formar hoje o engenheiro do amanhã"

reduzir a alta evasão já identificada entre discentes dos anos iniciais (MACAMBIRA, 2014) - e mais seguro em comparação a eventos anteriores.

No que tange à maior adesão estudantil, é válido apontar que o Material de Apoio disponibilizado resume de forma didática e concisa os principais conceitos necessários para a montagem de um talude. Dentre as informações apresentadas no Material, vale listar: conceituações introdutórias sobre solos e obras de terra; métodos para classificar os solos quanto à sua compacidade e granulometria, laboratoriais e empíricos; definições quanto aos ângulos de atrito, coesão e tensões efetivas às quais os solos estão submetidos. De praxe, o trabalho em equipe exercitado durante o concurso pelos grupos competidores permite que sejam desenvolvidas competências sociais entre os discentes que dificilmente são estimuladas na sala de aula tradicional.

A maior segurança, por sua vez, reside na baixa carga suportada pelos taludes. As simulações realizadas no GeoSlope ${ }^{\circledR}$ indicaram que os taludes modelados suportariam aproximadamente $30 \mathrm{~kg}$, cerca de dez vezes menos do que a carga suportada em concursos anteriores (ZORZAN et al, 2017). Reafirma-se, portanto, o compromisso do PET Engenharia Civil da UFJF em desenvolver um concurso mais seguro (a equipe vencedora rompeu o talude com $28 \mathrm{~kg}$ ).

Os pontos positivos da atividade foram reconhecidos, também, pelos próprios estudantes que competiram ou somente assistiram ao evento (a Figura 4, a seguir, ilustra alguns momentos do concurso).

Figura 4 - Concurso de Taludes 2019.

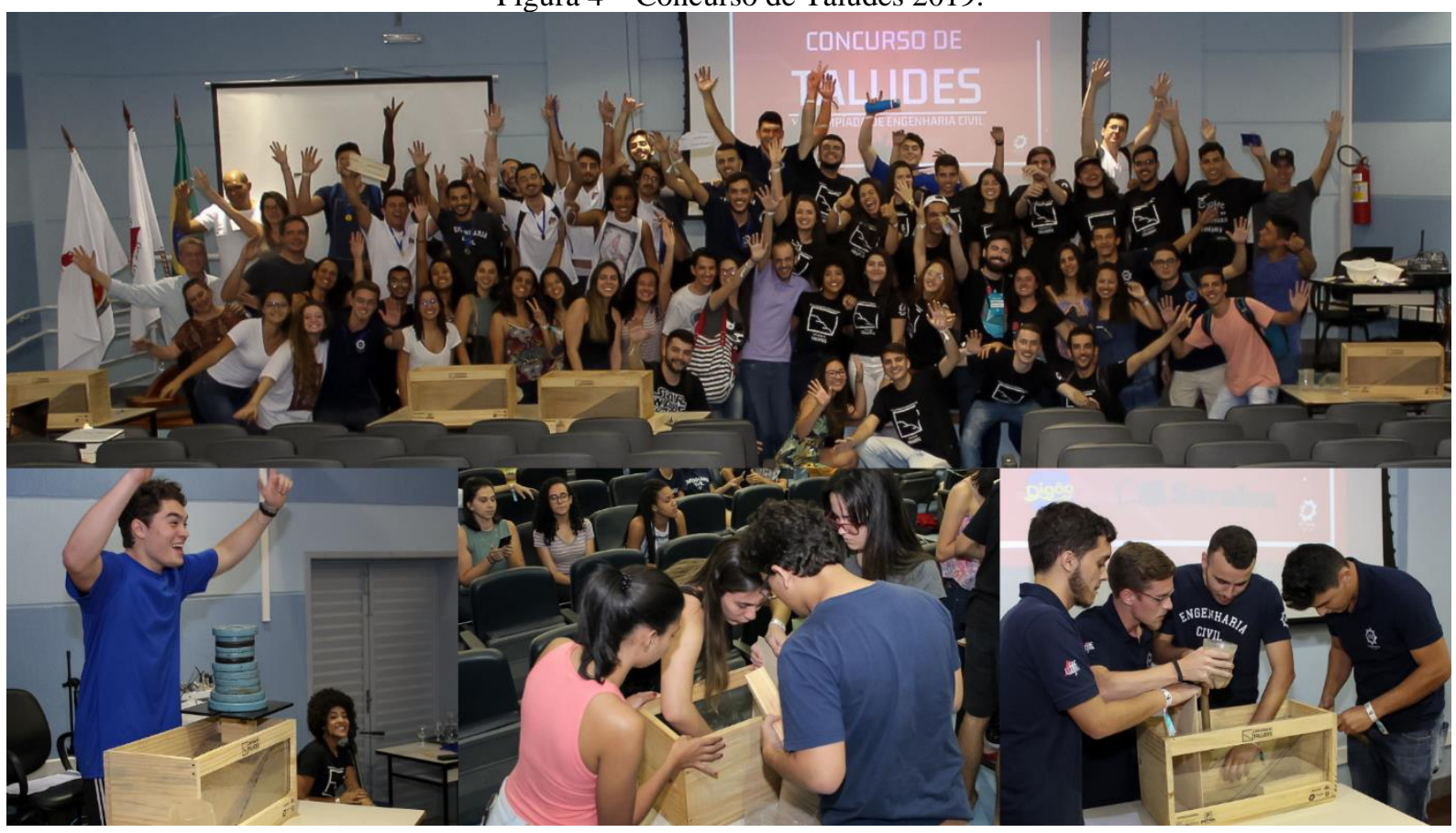

Fonte: Arquivo interno.

Por mais que os taludes construídos no concurso não possam ser utilizados para simular taludes reais, visto que não foi utilizado solo fidedigno ao que é vivenciado em obras de Engenharia, os discentes que responderam ao feedback on-line da atividade avaliaram a atividade como boa $(28,6 \%)$ ou excelente $(71,4 \%)$, incluindo avaliações dos competidores e espectadores. De modo geral, os feedbacks escritos resumem-se em elogios e pedidos por novas edições. Um dos discentes sugeriu que o peso na nota em relação a carga suportada 
pelo talude fosse aumentado, visto que a resistência a cargas está diretamente relacionada à eficácia de um talude.

\section{CONCLUSÃO}

O artigo ilustrou o concurso desenvolvido pelo PET Engenharia Civil da UFJF para incentivar o aprendizado sobre Engenharia Geotécnica. Em linhas gerais, a competição reuniu 8 (oito) grupos de estudantes de variados cursos de Engenharia para construir um talude em dimensões reduzidas dentro de uma caixa de madeira. Materiais para estudo foram produzidos e disponibilizados após a inscrição dos grupos competidores a fim de nivelar o conhecimento técnico dos discentes.

O solo utilizado na competição foi areia seca de granulometria majoritariamente média, obtido após secagem em estufa e peneiramento de cerca de $500 \mathrm{~kg}$ de areia natural simples. Após modelagem computacional, observou-se que taludes construídos com o material selecionado suportaria cerca de $30 \mathrm{~kg}$, ou seja, uma carga cerca de 10 (dez) vezes menor que aquela suportada em concursos anteriores de outras universidades.

Visto que a alta carga suportada pelo solo apresentava potenciais riscos à integridade física dos participantes em versões anteriores da atividade, a nova versão apresentada pelo PET Engenharia Civil da UFJF reduz as dimensões das obras de terra, utiliza materiais com menor resistência e contribui para a aprendizagem ativa de estudantes de todos os períodos da Engenharia Civil. Dessa forma, transformou-se um concurso quase extinto nas universidades brasileiras em um evento seguro e de fácil execução pelos participantes.

\section{REFERÊNCIAS}

CARVALHO, Y. M. et al. O Programa de Educação Tutorial como agente transformador e modulador de competências de um engenheiro. In: XLVII Congresso Brasileiro de Educação em Engenharia e II Simpósio Internacional de Educação em Engenharia da ABENGE, 2019, Fortaleza - CE. Anais... Fortaleza: ABENGE, 2019. 10 p.

COSTA, A. de L. Ponte de Macarrão. Revista Tecnológica da Universidade Santa Úrsula. v. 2, n. 1, p. 21-38, jan/jun 2019.

MACAMBIRA, I.Q.; ATHAYDE, L. S. Reprovação na disciplina cálculo nos cursos de engenharia: análise de dados e métodos minimizadores. In: XLII Congresso Brasileiro de Ensino de Engenharia, 2014, Juiz de Fora - MG. Anais... Juiz de Fora: ABENGE, 2014. 15 p.

OLIVEIRA, M. A. et al. Concurso Mola. In: IV Congresso Nacional dos Grupos PET de Engenharia Civil, 2017, Fortaleza - CE. Anais... Fortaleza: Galoá, 2017. 5 p. DOI: 10.17648/conpet-2017-60254

OLIVEIRA, V. F. As inovações nas atuais diretrizes para a Engenharia: estudo comparativo. In: OLIVEIRA, V. F. (org). A Engenharia e as novas DCNs: oportunidades para formar mais e melhores engenheiros. 1. Ed., Rio de Janeiro: LTC, 2019. p. 66-85. 
"Os desafios para formar hoje o engenheiro do amanhã"

PET ENGENHARIA CIVIL - UFJF. XV Olimpíada de Engenharia Civil: Concurso de Taludes. Edital. 2019. Disponível em: <https://www.ufjf.br/petcivil/linhas-de-pesquisa /concursos-2/6725-2/>. Acesso em 28 mai. 2020.

PINTO, C. de S. Curso Básico de Mecânica dos Solos. $3^{\text {a }}$ edição. Oficina de Textos, 2002.

ZORZAN, L. G. et al. Competições no Ensino da Engenharia Geotécnica: A Experiência do Desafio de Taludes da UFPR. In: XLV Congresso Brasileiro de Educação em Engenharia, 2017, Joinville - SC. Anais... Joinville: ABENGE, 2019. 10 p.

\section{ACTIVE LEARNING FROM COMPETITIONS: SLOPE CONTEST}

Abstract: To perform competitions to encourage active learning in Engineering courses is a common thing in Brazilian educational institutions, since they benefit both organizers and competitors. The Slope Contest, in particular, enables practical learning of geotechnical concepts. Since previous contests performed in some Brazilian universities presented difficulties regarding the participants' safety, the PET Engenharia Civil from UFJF prepared its own version of the competition to encourage the contest to be held. This paper summarizes the organization and the results obtained with the event, which was acclaimed by its participants. Thus, an almost extinct activity became a safe and practical event for participants.

Keywords: Tutorial Educational Program. Geotechnical Engineering. Engineering Education. Challenges. 